\title{
Estudo de parasitoses intestinais em moradores de corumbá, Mato Grosso do Sul, Brasil
}

As doenças causadas por enteroparasitas intestinais, helmintos e protozoários, são comuns no mundo, pois, acometem adultos e principalmente as crianças atingindo altos índices de contaminações, as parasitoses estão entre os grandes problemas medico-sanitários, sendo mais frequente em países subdesenvolvidos pela deficiência de saneamento básico. O presente estudo teve como objetivo diagnosticar a ocorrência de parasitoses intestinais em escolares de 05 a 15 anos e adultos a partir de 16 anos na Escola Municipal Izabel Correia de Oliveira, Escola Estadual Tilma Fernandes Veiga e na Estratégia Saúde da Família, (ESF), na cidade de Corumbá, Mato Grosso do Sul, Brasil. Foram coletados 200 amostras fecais mediante a autorização da diretora e agentes de saúde sendo, 100 de crianças e 100 de adultos realizada pela equipe do laboratório de Parasitologia da Universidade do Estado de Mato Grosso - UNEMAT, Brasil. O material fecal foi etiquetado e enumerado como local de coleta, idade e sexo e acondicionadas em caixas térmicas com gelo em seguida encaminhado para o laboratório de Parasitologia da UNEMAT. Para a análise laboratorial foi utilizado o método de Hoffmann ou sedimentação espontânea, na sequencia foram preparadas lâminas e analisadas no microscópio óptico em objetiva de $10 \mathrm{x} \mathrm{e} 40 \mathrm{x}$ onde foi possivel visualizar cistos de protozoários e ovos de helmintos. Das 200 amostras de fezes de humanos 111 foram negativas e 89 positivas para ao menos uma espécie de parasitas intestinais, obteve uma prevalência de 86,90 para protozoários dentre eles foram E. coli 34,83\% seguido de e. nana, $24,70 \%$, Giardia lamblia 20,22\%, E. histolytica $16.85 \%$, \%, Blastocystis spp. 3,37\% e Sarcocystis spp. $3,37 \%$. Helmintos obteve $13,10 \%$, sendo o mais prevalência Trichuris sp com $7,80 \%$ seguido do Acaris lumbricoides, $4,49 \%$, Enterobius vermiculares 1,12\%, Taenia sp. 1.12\% Fasciola hepatica 1,12\%. Dentre os parasitas encontrados constatou maior prevalência para o sexo feminino $57 \%$, para faixa etária obteve 58,50 de positividade para crianças de 05 a 15 em relação os adultos a partir de 16 ano $28,20 \%$, e ainda $65 \%$ da população estudada estão monoparasitadas e $34 \%$ se encontra poliparasitadas. Frente aos resultados foi possível perceber uma alta positividade na população estudada contaminada por parasitas intestinais, indica que o município de Corumbá MS precisa de maior investimento de saneamento básico, e a população necessita de melhores condições de hábitos de higiene pessoal-sanitária, pois a profilaxia é das medidas preventivas não só pela ausência da doença mas pelo bem estar das famílias.

Palavras-chave: Enteroparasitoses; Diagnóstico coprológico; Pantanal; Corumbá.

\section{Study of intestinal parasites in residents of Corumbá, Mato Grosso do Sul, Brazil}

\begin{abstract}
The diseases caused by intestinal intestinal parasites, protozoa and helminths, are common in the world therefore affect adults and especially children reaching high levels of contamination, the parasites are among the great medical and health problems, being more common in underdeveloped countries by deficiency sanitation. This study aimed to diagnose the occurrence of intestinal parasites in school $05-15$ years and adults from 16 at the Municipal School Isabel Correia de Oliveira, State School Tilma Fernandes Veiga and in the Family Health Strategy (ESF), in the city of Corumbá, Mato Grosso do Sul, Brazil. We collected 200 fecal samples with the permission of the director and health workers being, 100 children and 100 adults conducted by the Parasitology Laboratory team at the University of the State of Mato Grosso - UNEMAT, Brazil. Fecal material was labeled and listed as the collection site, age and sex and packed in coolers with ice then taken to the laboratory of Parasitology of UNEMAT. For laboratory analysis was used Hoffmann method or spontaneous sedimentation in the sequence were slides prepared and analyzed in the light microscope at 10x objective and $40 \mathrm{x}$ where it was possible to view protozoan cysts and helminth eggs. Of the 200 samples of human faeces were 111 negative and 89 positive for at least one kind of intestinal parasites, has obtained a prevalence of 86.90 to protozoa were among them E.coli followed and $34.83 \%$. E.nana, $24.70 \%, 20.22 \%$ Giradia lamblia, E. histolytica $16.85 \%$ Blastocystis $3.37 \%$ and $3.37 \%$ Sarcocystis. Helminths obtained $13.10 \%$, the most prevalent Trichuris sp with $7.80 \%$ followed by Ascaris lumbricoides, $4.49 \%, 1.12 \%$ Enterobius vermicularis, Taenia sp 1.12\% liver Faciola 1.12\%. Among the parasites found found higher prevalence in females $57 \%$, for age group obtained 58.50 positivity for children $05-15$ regarding adults from 16 years $28.20 \%$, and even $65 \%$ of the study population They are monoparasitadas and $34 \%$ is multiinfested frequent. Based on the results it was possible to perceive a high positivity in the study population infected by intestinal parasites, it indicates that the Municipality of Corumbá MS needs greater sanitation investment, and the population needs better standards of personal hygiene and health habits as prophylaxis is the preventive measures not only the absence of disease but the welfare of families.
\end{abstract}

Keywords: Intestinal parasites; Coprological Diagnosis; Pantanal; Corumbá.

Raquel Santos Batista da Silva (D) Universidade do Estado de Mato Grosso, Brasil http://lattes.cnpq.br/0664242062263111 http://orcid.org/0000-0003-1456-1979 raqquelsantos@hotmail.com

Antonio Francisco Malheiros (D)

Universidade do Estado de Mato Grosso, Brasil http://lattes.cnpq.br/9067970026570376 http://orcid.org/0000-0001-8169-0557 malheiros@unemat.br

Debora Pereira dos Santos (iD

Universidade do Estado de Mato Grosso, Brasil http://lattes.cnpq.br/8689908252924334 http://orcid.org/0000-0001-5738-770X

debora.pereira.1@hotmail.com

\section{Jeffrey Jon Shaw (iD)}

Universidade do Estado de Mato Grosso, Brasil http://lattes.cnpq.br/4665897914902853 http://orcid.org/0000-0002-7008-1972 jayusp@hotmail.com

Marta dos Santos Miranda de Araújo Universidade do Estado de Mato Grosso, Brasil http://lattes.cnpq.br/0599114436341749 http://orcid.org/0000-0002-3165-8230 martamiranda2@hotmail.com

Maria de Fátima de Almeida de Moraes (iD Universidade do Estado de Mato Grosso, Brasil http://lattes.cnpq.br/3126431241350186 http://orcid.org/0000-0002-4021-9221

enf.fatimamoraes@gmail.com
Wilton Nelson Lançoni de Campos Universidade do Estado de Mato Grosso, Brasil http://lattes.cnpq.br/1256279540505939 http://orcid.org/0000-0003-3165-611X wiltonlanconi@gmail.com

\section{Referencing this:}

SILVA, R. S. B.; MALHEIROS, A. F.; SANTOS, D. P.; SHAW, J. J.; ARAÚJO, M. S. M.; MORAES, M. F. A.; CAMPOS, W. N. L.. Estudo de parasitoses intestinais em moradores de corumbá, Mato Grosso do Sul, Brasil. Revista Ibero Americana de Ciências Ambientais, v.10, n.2, p.109128, 2019. DOI: http://doi.org/10.6008/CBPC21796858.2019 .002 .0010 


\section{INTRODUÇÃO}

As doenças causadas por enteroparasitas intestinais, helmintos e protozoários, são comuns no mundo, pois, acometem adultos e principalmente as crianças atingindo altos índices de contaminações sendo responsável por 2 a 3 milhões de óbitos por ano, porém as parasitoses estão entre os grandes problemas medico-sanitários, sendo mais frequente em países subdesenvolvidos pela deficiência de saneamento básico (VINHA, 1975; REY, 2001).

Segundo Rey (2001), os parasitas intestinais estão frequentes na população em diversas regiões da América Latina e na África, pois, na grande maioria de exames coproparasitológicos comprova que existem pessoas contaminadas por pelo menos uma espécie de parasitas, o que pode interferir no crescimento e desenvolvimento cognitivo em crianças e, nos adultos perda de dias de trabalhos em consequências dessas parasitoses sendo umas das principais causas de mortes no mundo (ROQUE et al., 2005).

Os parasitas intestinais acometem doenças nos seres humanos e também nos animais, podendo causar risco à saúde pública por ser uma zoonose, pois, a convivência do ser humano com animais de estimação é um dos fatores para transmissão dos parasitas, com mais ênfase nas as famílias de baixa renda, ou seja, famílias pobres (FARIAS et al.,1995; ZAIDEN et al., 2008).

No Brasil, estudos mostram altos índices de contaminação por parasitas intestinais, tanto em humanos quanto em animais, as doenças parasitárias são consideradas endêmicas no País, porém estão mais acentuadas nas famílias mais pobres devido à falta de saneamento básico, precárias condições de moradias, falta de água tratada e ingestão de alimentos contaminados, considera-se que atualmente é um problema de saúde pública (MELO et al., 2010).

Segundo Ferreira et al. (2002), os altos índices de parasitoses se encontram distribuídos em várias regiões com temperatura mais elevada, o que "pode estar relacionado às condições ambientais e climáticas particulares de cada local", favorecendo assim a proliferação e sobrevivência de ovos, larvas e cistos e, concomitantemente a disseminação de parasitas específicos (MENEZES et al., 2012).

Na zona rural há também uma prevalência significativa de pessoas acometidas por infecções parasitárias, pois, os mesmos estão associados às precárias condições socioeconômicas das famílias e infraestruturas do local, inexistência de água tratada, rede de esgoto, dejetos depositados a céu aberto, onde são mais escassos os trabalhos de assistência médica e vigilantes sanitários. Em consequência disso essas pessoas acabam ingerindo alimentos contaminados por não ter o conhecimento e informações sobre parasitas (VISSER et al., 2011; SILVA et al., 2001).

Os parasitas intestinais estão intimamente ligados à pobreza, pois, vem causando entidades mórbidas principalmente em crianças das periferias, favelas, creches e escolas, por serem lugares que circulam muitas pessoas facilitando a disseminação dos parasitas, outro fator é a falta do hábito de higiene pessoal e sanitário, no entanto acometem pessoas em qualquer idade, mas, as crianças são mais suscetíveis aos riscos de contaminação, até mesmo por falta de informações da família, como lavar as mãos, não andar descalço, ingerir água e alimento tratados (LUDWIG et al., 2012). 
No entanto a forma de contaminação de ovos de Helmintos e cistos de Protozoários se dá por via fecal-oral ou pela penetração de larvas na pele (BRITO et al., 2013; NEVES, 2011). As infecções parasitárias agravam para os sintomas gastrointestinais causando diarreia, vômitos, dores abdominais, a desnutrição por alimentação inadequada associada as infecções parasitárias causam anemia por falta de ferro, interferindo no desenvolvimento físico e mental da criança em várias fixas etárias, e por fim acarretando dificuldades no aprendizado escolar e, em muitos casos há complicações que leva o indivíduo a óbito (PEDRAZZINI et al., 1988; MELO et al., 2010; COSTA et al., 2014).

Portanto há falta de políticas públicas para implementação de projetos educativos com a participação da população para o controle das infecções, pois, a profilaxia é uma das mediadas que podem ser usadas para prevenção de contaminação por parasitas intestinais proporcionando melhor condições de saúde (VINHA, 1975).

No entanto, foi realizado um estudo de parasitoses intestinais em moradores do Município de Corumbá, Mato Grosso do Sul, em duas Escolas Municipais e uma Unidade Básica da Saúde (ESF), com o objetivo de diagnosticar por meio de métodos Laboratoriais a ocorrência de Helmintos e Protozoários em crianças e adultos.

Desta forma, o objetivo geral deste trabalho é diagnosticar a ocorrência de parasitoses intestinais (helmintos e protozoários) por meio de métodos laboratoriais em crianças e adultos matriculados na Escola Municipal Izabel Correia de Oliveira, Escola Estadual Tilma Fernandes Veiga e na Estratégia Saúde da Família, (ESF), na cidade de Corumbá, Mato Grosso do Sul, Brasil.

\section{REVISÃO TEÓRICA}

A parasitologia é extremamente importante, pois, é uma ciência que estuda os parasitas intestinais, uma vez que os mesmo vivem dentro ou fora do corpo de um hospedeiro. Os parasitas como qualquer organismo dependem de outro ser vivo, ou seja, de um hospedeiro para sobreviver, reproduzir, extrair alimentos e abrigo sendo que esta associação pode ser nociva ou não ao hospedeiro (NEVES, 2005; CIMERMAN, 2001.)

Neves (2005) também afirma que o "parasitismo é uma associação entre seres vivos, sendo o parasita um agressor e o hospedeiro é o que alberga o parasita". Desse modo havendo prejuízo em um dos organismos associados.

Segundo Neves (2005) alguns parasitas intestinais vivem em associações com um hospedeiro de forma que nenhum deles causa malefício é o que denominamos de Comensalismo, dentre eles algumas espécies de protozoários. Porém, ainda existe uma classificação de parasitismo assintomático, ou seja, parasitas comensais quando o hospedeiro está parasitado e não apresenta sintomas da doença, e sintomático quando o hospedeiro parasitado apresenta sintoma da doença (MORAES, 1982).

Os parasitas intestinais são de importância econômica e social, no entanto vem causando enfermidades na população mundial. Segundo a (OMS) organização mundial de saúde "cerca de 980 milhões de pessoas estão parasitados por Áscaris lumbricoides, 200 milhões pelo Schistosoma mansoni", (LODO et 
al., 2010). Cerca de "700 milhões por Trichuris trichiura e Ancilostomideos, 400 milhões parasitados pelos protozoários Giardia lamblia e 200 milhões por Entamoeba histolytica e Eantamoeba coli" (CINERMAN, 2001; GELATTI et al., 2013).

Os parasitas intestinais estão associados à falta de saneamento básico decorrente de países subdesenvolvidos, no entanto, vem acometendo as famílias menos desfavorecidas com nível econômico baixo, sendo que as crianças são vulneráveis as infecções a partir de quando para de amamentar, outra faze crítica é na idade escolar, por não ter um comportamento formado sobre hábito de higiene pessoal, e o ambiente escolar é um dos lugares propício para a contaminação por esses parasitas (LUDWIG et al., 1999).

Em pessoas idosas a ocorrência de parasitoses é bem menor, pois, com aumento da idade há uma mudança no comportamento de higiene pessoal e o sistema imunológico mais formado não são tanto suscetíveis aos parasitas quanto às crianças que tem seu sistema imunológico 'baixo' (GUERRERO et al., 2005). Estudos mostram que as doenças parasitárias ainda são endêmicas no Brasil, variando de acordo ao ambiente favorável para a proliferação dos parasitas em cada região, porém, a taxa de morbidade está relacionada à falta de infraestrutura sanitária, uma vez que os veículos de transmissão dos parasitas são a falta de água e rede de esgoto não tratado, ingestão dos alimentos crus contaminados e contato pelo solo contaminado por fezes, pois, a contaminação se dá pela ingestão do cisto de Protozoários, ovos e larvas de Helmintos (MARZAGÃO et al., 2010).

No Brasil, um dos fatores que também contribui para transmissão significativa dos parasitas é o crescimento populacional desordenado, a migração causa aglomeramento de pessoas vindo das áreas rurais para as cidades, ocupando as periferias e favelas. Em consequência do acúmulo dessas pessoas associadas às condições de moradias precárias, a falta de serviço sanitário causam o acúmulo de lixo e concomitantemente a disseminação de parasitas intestinais, dentre ele os protozoários e helmintos (NEVES, 2005). O mesmo autor ainda afirma que, "a transmissão e a manutenção de uma doença na população humana são resultantes do processo interativo entre o agente etiológico, o meio ambiente e o hospedeiro humano".

No entanto as taxas de infecções causadas por parasitas intestinais são altas em diversas regiões de Países subdesenvolvidos, estudos mostram que essas infecções acometem bilhões de pessoas sendo que a maioria são crianças, em idades escolares, creches, favelas e pessoas que vivem nas periferias das cidades sem acesso ao saneamento básico. No entanto, as helmintíases e as protozoozes são importantes indicadores das condições socioeconômico, sanitário e educacional da população (SANTOS et al., 2010; RODRIGUE et al., 2013)

Dentre as infecções parasitárias destacam-se as geohemintíases causadas por helmintos (Ascaris lumbricoides, Trichuris trichura e Ancilostomideos), e as infecções por protozoários enfatiza-se a Giardíase, causada pela Giardia e Amebíase pela Entamoeba histoytica, Porém, são consideradas como doenças negligenciadas, pois, estão associadas à pobreza, embora não apresentam altas taxas de mortalidade, mas sim altas taxas de morbidade (ANDRADE et al., 2010). 
O autor citado ainda afirma que as infecções causadas por estes parasitas, agravam para os sintomas gastrointestinais causando dores abdominais diarreias persistentes, vômitos, podendo interferir na absorção de nutrientes, evoluindo para o sangramento intestinal, perda de apetite ocasionando o quadro de desnutrição e anemia, em alguns casos agrava para obstrução intestinal dependendo da carga parasitária que o hospedeiro está albergando pode levar a óbito (NEVES, 2011).

Segundo Andrade et al. (2011) o poliparasitismo é uma condição em que um hospedeiro está parasitado por duas ou mais espécies de parasitas intestinais que podem ser patogênica ou não, entretanto estudos realizados em várias regiões do País, mostram altos índices de pessoas contaminadas por mais de uma espécies de parasitas, o que aponta para um maior risco de contaminação ambiental contribuindo para a disseminação doença.

Segundo Vasconcelos et al. (2011) em um estudo realizado no Estado do Pará com 383amostras fecais de criança de quatro a 12 anos de idade, 233 apresentou positividade por mais de uma espécie de parasitas, obteve assim uma porcentagem de $18 \%$, para criança poliparasitados, com uma porcentagem $(21,9 \%)$ para Ascaris lunbricoides e $(30,3 \%)$ para Entamoeba sp, o que estão relacionados a falta de água potável, rede de esgoto e higiene pessoal.

Guerreiro et al. (2005) realizou um estudo com pessoas idosas do Norte do Estado da Amazônia, onde foram analisadas 81 amostras fecais, sendo (43,2\%) apresentou monoparasitados, (23,5\%) biparasitados e $(62,2 \%)$ poliparasitados. No entanto os parasitas mais frequentes foram Ascaris lunbricoides $(35,2 \%)$ seguido de Entamoeba coli (18,2\%) Trichuris trichiura (16,0\%) e Entamoeba histolytica (4,5\%). Portanto os parasitas intestinais tanto em adultos quantos em crianças vem causando problema a saúde, o que é preocupante, pois ainda é um problema de saúde pública.

Segundo Teixeira et al. (2014) a falta de saneamento básico como água tratada, instalações sanitárias, rede de esgoto, coleta adequada do lixo e higiene pessoal são fatores primordiais que vem colocando a população de baixo nível socioeconômico em risco à saúde, onde as doenças infecciosas continuam a configurar as causas de 'morbidade e mortalidades no Brasil'.

De acordo com o autor citado a pesquisa sobre o saneamento básico realizada pelo (IBGE, 2010) relata que, em 2008 "aproximadamente $20 \%$ da população brasileira não dispunha de rede geral de abastecimento de água e 50\% da população depositavam o lixo a céu aberto", esta deficiência significativa da falta de água tratada bem como da rede de esgoto sanitário eram as causas de morte de15 mil pessoas por ano decorrente das doenças relacionada ao saneamento básico, dentre elas as infecções causadas por helmintos e protozoários.

Entretanto, segundo a Embrapa (2005) nos estados brasileiros $80 \%$ dos esgotos domésticos e industriais são lançados em rios sem tratamento adequado, significa que a situação das condições de saneamento básico em várias cidades brasileiras ainda são precárias. Atualmente a prevalência dessas doenças parasitárias ainda são significativa e negligenciadas devido essas fragilidades nos sistemas públicos do País, pois há necessidade de intervenções de políticas públicas e práticas educativas que visa a promoção 
e proteção à saúde não só pela ausência da doença mas sim pelo bem estar e melhoria na qualidade de vidas das pessoas que estão sob a desnutrição e abaixo a linha da pobreza (SOUZA et al., 2010).

\section{Principais parasitas intestinais}

Geohelmintíase são infecções causadas pelos helmintos como Ascaris lumbricoides, Trichuris trichiura, e ancilostomídeos, que são parasitas que utiliza parte do solo para completar sua reprodução, são de grande importância, pois parasitam milhões de pessoas e causam problema de saúde pública (WHO, 2002; PEDROSA et al., 2014). Os helmintos são vermes grandes com uma organização complexa, porém, com estádios larvais, medindo de 100 a $200 \mu \mathrm{m}$, e vermes adultos que podem variar de milímetros até alguns metros, são muitos comuns em clima quente e temperado (MARTINS, 2012).

\section{Ascaridíase}

É causada pelo Ascaris lumbricoides, dentro Filo Nematelmintos da Classe Nematoda, são de interesses na medicina e na saúde pública, são vermes que possui a forma do corpo alongados se afilam nas duas extremidades, possui dimorfismo sexual, ou seja, sexo separados, os machos são maiores que as fêmeas e o embrião se desenvolve dentro do ovo no meio exterior, o verme adulto pode variar de 20 a $30 \mathrm{~cm}$ de comprimento (MARTINS, 2012; NEVES, 2011).

No entanto é do tipo monoxênico (possui um único hospedeiro), a transmissão ocorre pela ingestão de água ou alimentos contaminado, principalmente água de córrego utilizado para irrigar hortas contaminando assim as verduras com ovos viáveis, após ingerir os ovos férteis, sofrem vários estágios de muda (estágio) e atravessam todo o trato digestório eclodem no intestino delgado, essas larvas atravessam a parede intestinal na altura do ceco, caindo na nos vaso linfáticos invadem o fígado entre 18 a 24 horas após a infecção (NEVES, 2011; REY, 2001; AVELAR, 2012).

Dentro de dois a três dias chegam ao coração e pulmão, posteriormente rompem os capilares e caiem nos alvéolos subindo pela árvore brônquica e traqueia onde chega na faringe podendo ser expectorada e fixando no intestino delgado, onde vão se tornar adultos, dentro de 60 dias alcançam a maturidade sexual e as fêmeas fecundadas são capazes de colocar até 200.000 por dia, esses ovos são com cerca de $50 \mu m$ de diâmetro e formato ovais. Geralmente a ascaridíase é assintomática por isso pode ser difícil diagnosticada, pois as alterações provocadas está relacionada pelo número de verme que infectam cada pessoa, acometem especialmente crianças com idade inferior a 12 anos (NEVES, 2011; REY, 2001; AVELAR, 2012).

\section{Ancilostomídeos}

São pequenos helmintos nematoides representantes do Filo Nemathelminthos, causam doenças chamada ancilostomose, pertencente à família Ancylostomatidae, ou mais especificamente por Necator americanus e Ancylostoma duodenale. As ancilostomoses humanas geralmente são negligenciadas, tem grande importância no contexto universal, pois são de ampla distribuição geográfica e representa um dos grandes problemas de saúde pública. Os Ancilostomideos apresentam ciclo biológico direto não necessita de 
hospedeiro intermediário, possui duas fase bem definidas: a primeira que se desenvolve no meio exterior sendo de vida livre, e a segunda desenvolve no hospedeiro definitivo que é fase parasitária (NEVES, 2006; 2010; REY, 2001).

A contaminação se dá pela penetração de larvas ativas através da pele ou passivamente por via oral, após penetrarem na pele, através da corrente sanguínea atinge a veia cava e chega ao coração e em seguida o pulmão chegam nos alvéolos pulmonares, essas larvas migram pelos bronquíolos atingindo a traqueia e laringe são deglutidas, chegando no intestino delgado onde se adquire a maturidade dentro de 30 dias após a infecção, onde ocorre a postura dos ovos em grande quantidade, estima -se que A. duodenale bote 20 a $30 \mathrm{mil}$ ovos/dia, podendo viver de seis a oito anos, já o $\mathrm{N}$. americanus bote $10 \mathrm{mil}$ ovos/dia e pode viver cerca de quatro a cinco anos, esses ovos são eliminados pelas fezes no meio exterior contaminando o ambiente, e em condições favoráveis dentro de 24 horas sofrem mudas e imediatamente eclodem e transformam em larvas filarióides que é a forma infectante. O período desde a penetração das larvas na pele até a eliminação dos ovos pelas fezes, varia de 35 a 60 dias (NEVES, 2006; 2011; REY, 2001).

No entanto as larvas ao penetrarem na pele além de causar lesões, os vermes adultos se fixam na mucosa do intestino delgado pela cápsula bucal e se alimentam do sangue, causando espoliações e agravando para sintomas abdominais, dor epigástrica, diminuição do apetite, indigestão, cólicas, indisposição, náuseas, vômitos, flatulência, diarreia sanguinolenta ou não e anemia, dependendo da carga parasitária e do estado nutricional do paciente, acometem mais frequentemente crianças acima de 6 anos e jovens até 15 anos, pois o parasita A. duodenale pode sugar 0,05-0,03 de sangue por dia e o N. americanus 0,01-0,04 (REY, 2001; NEVES, 2006; 2010; LODO et al., 2010).

\section{Trichuridíase}

Doença causada pelo verme nematódeos Trichuris trichura pertencente a ordem Trichurida, tem sua distribuição cosmopolita, apresenta grande importância médica e veterinária, pois parasitam cerca de 1 bilhão de pessoas no mundo, das quais aproximadamente 350 milhões na idade inferior a 15 anos, esse geohelminto é mais prevalente em regiões de clima quente e úmido onde as condições sanitárias são precárias favorecendo assim a contaminação ambiental e a sobrevivência dos ovos (NEVES, 2006, 2010; 2011).

É do tipo monóxeno, sendo o homem o principal hospedeiro, os adultos medem de $3 \mathrm{a} 5 \mathrm{~cm}$ de comprimento sendo os machos menores que as fêmeas e apresentam dimorfismo sexual, são parasitas do intestino grosso de humanos. A transmissão se dá pela ingestão de ovos na água e alimento contaminado com fezes, pode ser disseminado também por moscas domésticas que carregam ovos na superfície externa do corpo de locais onde foram depositadas fezes até os alimentos, após a ingestão os ovos contendo larvas infectantes eclodem penetrando na mucosa intestinal onde completam seu desenvolvimento até vermes adultos, se reproduz sexuadamente e, a fêmea fecundada elimina de 3.000 a 20.000 por dia, medindo de 50-55 $\mu \mathrm{m}$ de comprimento por $22 \mu \mathrm{m}$ de largura de formato elíptico, esses ovos são eliminados para o meio 
ambiente pela fezes para se tornar infectantes, sob condições favoráveis de temperatura e humidade podem permanecer viáveis por longo período de tempo (NEVES, 2006; 2010; 2011; REY, 2001).

O período de tempo entre a infecção até a eliminação de ovos nas fezes pelo hospedeiro é de aproximadamente 60 a 90 dias. A grande maioria dos casos de pessoas infectadas leves por Trichuris trichura é assintomáticos, no entanto a gravidade depende da carga parasitária bem como idade e estado nutricional, nas infecções crônicas o sintomas podem ser diarreia intermitente com presença de muco ou sangue, dor abdominal, anemia e desnutrição grave (NEVES, 2010; 2011; REY, 2001).

\section{Protozoários}

O sub- reino Protozoa é constituído por cerca de 60.00 espécies, das quais aproximadamente 10.00 espécies são parasitas dos mais variados animais e apenas algumas dezenas infectam humanos. Os protozoários são organismo unicelulares eucariontes, e apresentam grandes variações, podendo ser esféricos, ovais ou alongados, alguns possui cílios outros flagelos, de acordo com sua atividade fisiológica possui fazes bem definidas sendo uma Trofozoitos que é forma ativa se alimenta e reproduz e Cisto que apresenta forma de resistência sendo infectante (NEVES, 2010; 2011).

\section{Giardíase}

Doença causada pela Giardia, protozoário flagelado parasita do intestino delgado de mamíferos, aves, répteis, e anfíbios, sendo um dos principais parasitas intestinais que infectam humanos. Destaca -se como um dos mais frequente nos inquéritos coprorasitológicos em diferente regiões de Países desenvolvidos, sendo negligenciada uma vez que está associada à pobreza e falta de saneamento básico, qualidade de água para o consumo (NEVES, 2010; 2011).

No entanto Giárdia é um parasita monoxênico e apresenta duas formas evolutivas, o trofozoito é encontrado no intestino delgado, sendo a forma responsável pelas manifestações clínicas da infeç̧ão, tem formato de uma pera medindo $20 \mu \mathrm{m}$ de comprimento por $10 \mu \mathrm{m}$ de largura com quatro pares de flagelos. O cisto é a forma responsável pela transmissão do parasita, sendo de formato oval medindo aproximadamente $12 \mu \mathrm{m}$ de comprimento e $8 \mu \mathrm{m}$ de largura, apresenta um parede cística resistente a certas variações de temperatura, umidade e ação de desinfetante, no citoplasma pode ser visualizado dois a quatro núcleos (NEVES, 2010; 2011).

A transmissão ocorre por via fecal-oral a partir da ingestão de cisto presente na água e alimentos contaminados com fezes, (verduras cruas e frutas mal lavadas), os alimentos também pode ser contaminados por moscas e baratas que transportam cistos, além da transmissão hídrica ocorre também a transmissão direta de pessoas a pessoas por meio das mãos contaminadas, o que é mais comum em aglomeramento de pessoas, após ingerido o cisto, passa por um processo de desencistamento que inicia no meio ácido do estômago e completa no duodeno e jejuno, onde ocorre divisões celulares e adquire a forma trofozoitos e em seguida se multiplicam e assim vivem aderido a mucosa do intestino, o ciclo se completa pelo encistamento do parasita. Entretanto a Giardia apresenta um quadro clínico que varia desde de indivíduo 
assintomático até sintomático, que pode apresentar diarreia aguda ou persistente, irritabilidade dor abdominal e má- absorção e perda de peso, pois acomete crianças de oito meses a 10-12 anos (NEVES, 2010; 2011; ZAIDEN et al., 2008).

\section{Amebas}

Grupos de protozoários que inclui espécies altamente patogênicas para os humanos como também espécies ditas comensais, entretanto as amebas que ocorrem em humanos pertencem ao filo Sarcomastigophora e subfilo Sarcodina, dentre as amebas destaca -se as de maior importância, pois causam problema de saúde pública como a Entamoeba histolytica, já espécies patogênicas como Entamoeba dispar, Endolimax nana e Entamoeba coli, são espécies comensais, embora são indicadores de contaminação (NEVES, 2006; ZAIDEN et al., 2008).

\section{Amebíase}

Infecção causada pelo agente etiológico Entamoeba histolytica, pois, são importante por sua ampla distribuição geográfica e alta incidência sobretudo em regiões tropicais, no entanto, causam problema de saúde pública e constitui a segunda causa de mortes por parasitoses, com uma taxa de aproximadamente 10.000 morte de pessoas por ano. É do tipo monoxênico, apresenta uma série de estágios, trofozoito que mede de 20 até $40 \mu \mathrm{m}$ geralmente com um núcleo, o pré-cisto apresenta formato oval ou arredondado sendo menor que o trofozoito, já metacisto é a forma multinucleada que sofrem divisões originando trofozoitos, o cisto é a forma infectante, são esférico ou ovais com tamanho entre 8 a $20 \mu \mathrm{m}$ os núcleos de um a quatro são bem visíveis (NEVES, 2010; REY, 2001).

A transmissão ocorre através da ingestão de cisto maduro em alimentos ou água contaminada por fezes, o consumo de verduras cruas e frutas é um dos veículos de cisto mais frequentes, os alimentos também podem ser contaminado por cisto transportados por patas de baratas e moscas, além disso a falta de higiene domiciliar pode disseminar cistos entre a família (NEVES, 2010; 2011; REY, 2001)

A infecção amebiana é de caráter cosmopolita e pode variam entre assintomático ou sintomático, após a ingerir o cisto maduro passam pelo estômago, quando chega ao final do intestino delgado onde ocorre o desencistamento, na sequencia origina o metacisto e posteriormente trofozoitos, migram para intestino grosso e se colonizam, em geral ficam aderido a mucosa do intestino se alimentando, o ciclo continua pelo encistamento onde vão ser eliminados pelas fezes. Causam sintomas como dor abdominal, colite não disentérica que se manifesta por duas a quatro evacuações por dia diarreica ou não, com fezes moles ou pastosas, pode ter complicações como perfurações, peritonite (inflamação do peritônio), hemorragias e inflamação intestinal pôs- disentéricas (NEVES, 2006; 2010; 2011; REY, 2001). 


\section{MATERIAIS E MÉTODOS}

\section{Área de Estudo}

A coleta das amostras fecais de adultos e de criança, nas duas Escolas Municipais e de uma Unidade Básica de Saúde, foi realizada pela equipe do Laboratório de Parasitologia da Universidade do Estado de Mato Grosso no município de Corumbá, Mato Grosso do Sul, Brasil. Segundo o Instituto Brasileiro de Geografia e Estatística (IBGE, 2010), Corumbá/MS (Fig. 01) foi Fundada no ano 1778, para impedir o avanço dos espanhóis pela fronteira brasileira em busca do ouro, o Arraial de Nossa Senhora da Conceição de Albuquerque, primeira denominação do vilarejo, se transformou no principal entreposto comercial da região. Foi elevada a Distrito em 1838 e a Município em 185.

O município de Corumbá está situado na margem direita do Rio Paraguai, no sul da região CentroOeste do Brasil, limita-se com Bolívia e Paraguai, inserido nos Biomas Cerrado e Pantanal, com aproximadamente $420 \mathrm{~km}$ da Capital Campo Grande MS, seu território está concentrado cerca de 60\% da região do pantanal, sendo a quarta cidade mais populosa de Mato Grosso do sul, o clima é tropical húmido com inverno seco e chuva no verão, Corumbá possui aproximadamente 107.347 habitantes, com área territorial de $64.962,720 \mathrm{~km}^{2}$, ocupando aproximadamente quase $20 \%$ da área do Estado. Situado nas

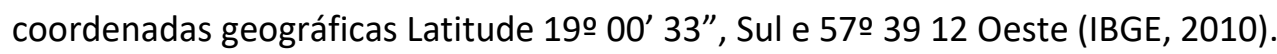

O Município de Corumbá na área da saúde conta com aproximadamente 39 estabelecimentos de saúde (SUS), com índice de desenvolvimento humano (IDHM) de 0,700. Na área da educação conta com um número de 19.647 alunos matriculados em Escolas do Ensino Fundamental, 4.099 nas Escolas do Estado (IBGE, 2010). Segundo a Embrapa, 2005 na cidade de Corumbá a situação do saneamento básico era precárias, uma vez que a principal fonte de abastecimento de água urbana é o rio Paraguai, porém não tinha estação para tratamento de esgoto nem aterro sanitário, o lixo doméstico e hospitalar era depositado no lixão.

Já em 2010 Segundo o Instituto Brasileiro de Geografia e Estatística (IBGE, 2010), o do Município de Corumbá MS ainda apresentava deficiência no saneamento básico, pois contava com cinco favelas com um total 5,767 pessoas residindo em 1,416 residências, o que é desproporcional ao números de pessoas por habitação, significa que essas pessoas vivem em aglomeramento, o que é mais preocupante que dentre essa favelas 33 residências não possuía sanitários nem acesso a água, e consequentemente não tinha coleta do lixo.

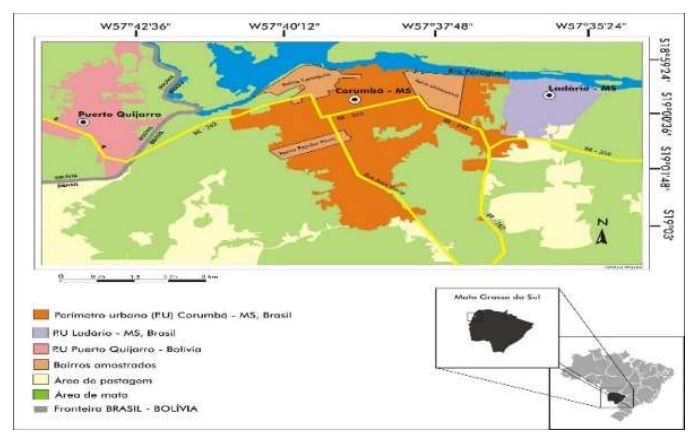

Figura 1: Localização do Município de Corumbá Estado de Mato Grosso do sul. 


\section{Amostras}

Para a realização deste estudo foi coletado material fecal de 100 crianças de 05 a 15 anos e 100 de adultos a partir de 16 anos nos três pontos distintos, na Escola Municipal Izabel Correia de Oliveira, Tilma Fernandes de Oliveira e na Unidade Básica de Saúde (Estratégia Saúde da Família) Enio Cunha totalizando assim 200 amostras.

No entanto a população estudada foram crianças e adultos onde o trabalho de coleta do material fecal realizada pela equipe do Laboratório de Parasitologia da Universidade de Mato Grosso foi mediante a autorização da direção das escolas e agentes de saúde, no entanto foram distribuíram potes coletores universal em um dia nos ponto mencionado e recolhido no dia seguinte, porém foi coletado só uma amostra tanto de crianças quanto de adultos. Após coletados, cada coletor universal foi devidamente etiquetado e numerado sequencialmente de 1 à 200 bem como local de coleta, idade e sexo, nos três locais de coleta (Fig. 2).

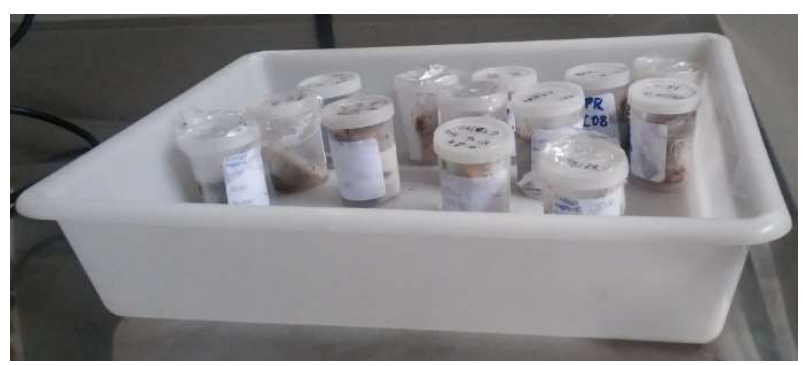

Figura 2: Coletores universal etiquetados e enumerados com amostras fecais de humanos coletados em Corumbá/MS.

As amostras fecais foram devidamente acondicionadas em caixas térmicas com gelo para serem conservadas e em seguida foi encaminhado ao Laboratório de Parasitologia da Universidade do Estado de Mato Grosso - UNEMAT, para processo de alíquota e análise coproparasitológico.

\section{Análise Laboratorial}

No Laboratório de Parasitologia da Universidade do Estado de Mato Grosso - UNEMAT, o material foi retirado das caixas térmicas e armazenados em geladeiras. Na sequência foram analisadas números das a mostras, local de coleta, consistência fecal como formada, diarreica e pastosa, e aspecto fecal como sanguinolenta fungada e normal bem como dados demográficos sexo e idade anotado em uma planilha, e em seguida foram feitas as alíquotas utilizando o método de (HOFFMANN et al., 1934) (Fig. 3), essa técnica consiste na sedimentação do material fecal misturado com água, pois é considerado um método eficiente de fácil execução para laboratórios com baixo custo.

No entanto após a sedimentação das fezes foi retirado a água e adicionado formol a 10\%, para conservação dos parasitas, onde esse material fecal foram depositados em tubos Falcon e armazenados em geladeira a $20^{\circ}$ c, com todos as informações necessárias (Fig. 4). Para a análise microscópica foi preparada uma lâmina de cada amostra (Fig.5), onde na mesma foi colocado uma gota do material fecal sedimentado e acrescentado com uma gota de lugol em seguida homogeneizando e coberto com uma lamínula. Na sequência as lâminas foram enumerada (Fig.6) de acordo as numerações dos tubos falcon e em seguida 
levadas ao Microscópio óptico em objetiva de 10x e 40x, onde foi possível visualizar ovos de helmintos e cistos de protozoários.

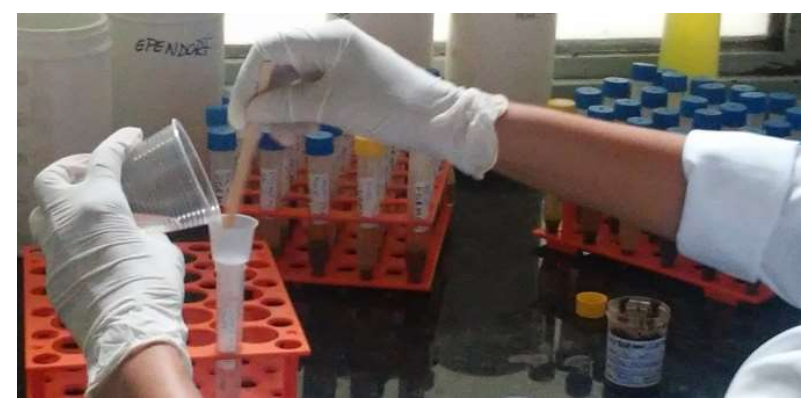

Figura 3: Procedimentos do Método de Hoffman das amostras fecais de humanos de Corumbá/MS.

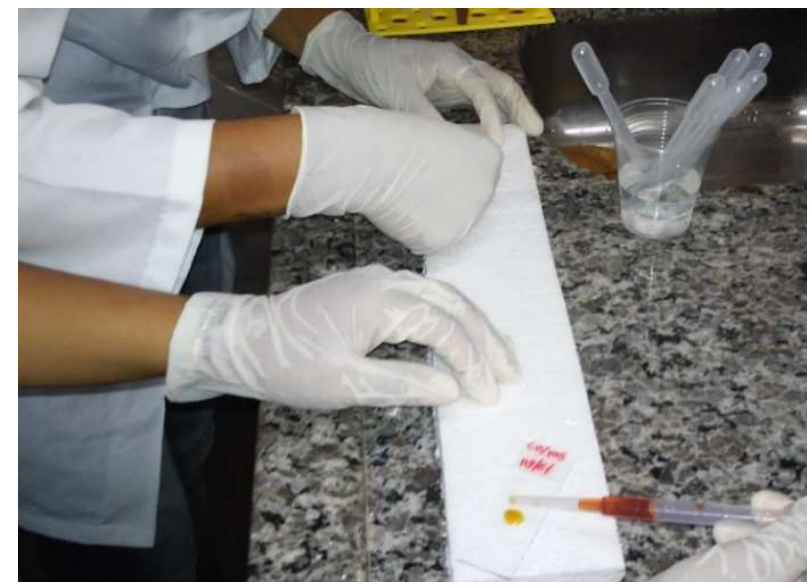

Figura 5: Processo de preparação das lâminas para leituras das amostras fecais de humanos de Corumbá/MS.

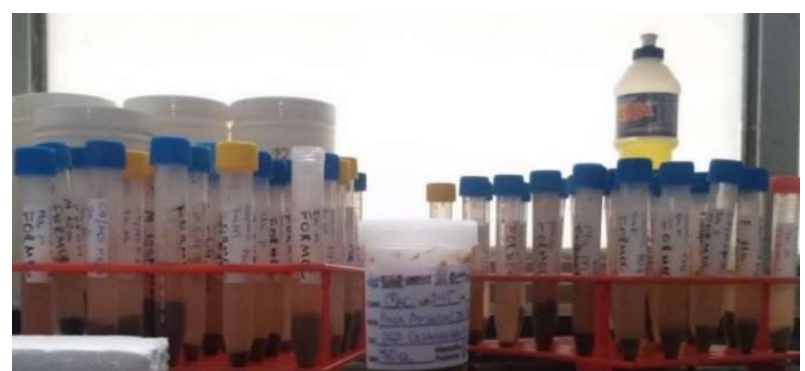

Figura 4: Material fecal de humanos conservado em formol $10 \%$ nos tubos Falcon da cidade de corumbá/MS.

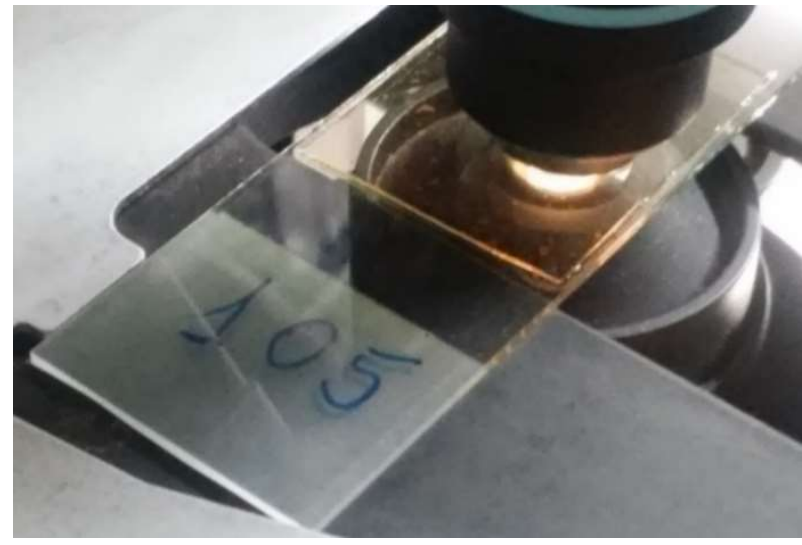

Figura 6: Lâminas enumeradas e preparadas para leituras com amostras fecais de humanos da cidade de corumbá/MS.

\section{Análise dos Dados}

As informações sobre quantidade, espécie dos parasitas foram anotados em uma planilha, por meio do Office Excel (2010), e para as análises estatísticas foi usado do teste Qui- quadrado $\left(x^{2}\right)$, para as duzentas amostras com significância $p<0,05$.

\section{Aspecto Ético}

O presente estudo faz parte do projeto "Biodiversidade das parasitoses intestinais proveniente de amostras fecais humanas e de cães de seis biomas brasileiros" aprovado pelo Comitê de Ética do Instituto de Ciências Biomédicas da Universidade de são Paulo - USP em 12 de Junho de 2013, sob parecer nº 310.501 (Anexo 1).

\section{RESULTADOS E DISCUSSÃO}

Foram analisadas um total de 200 amostras de fezes humanas onde dessas 111 (55,50\%) foram negativas e 89 (44,50\%) foram positivas para ao menos um parasitas intestinais (Fig.7). Estes resultados assemelha com os de Silva et al. (2010) que realizou um estudo em uma escola na cidade de Nova Alvorada de sul no mesmo estado MS com 93 crianças na faixa etária entre 05 a 12 anos de idade, obteve um total 
35,48\% de positividade, ainda Visser et al. (2011) também realizou um trabalho com pessoas cadastrada no Programa Saúde da Família (PSF) da cidade de Manaus no Estado do Amazonas, das 362 exames parasitológico obteve uma prevalência de positividade para 44,2\%.

Em comparação com outros resultados na literatura como o trabalho de Silva (2001) em crianças de um Centro de Saúde Cícero Idelfonso/MG, foi constado a ocorrência de 63,3\% e 58/\% em escolares no município de Caxias do Sul (BASSO et al., 2008) a frequência para este trabalho revelou- se relativamente baixo.

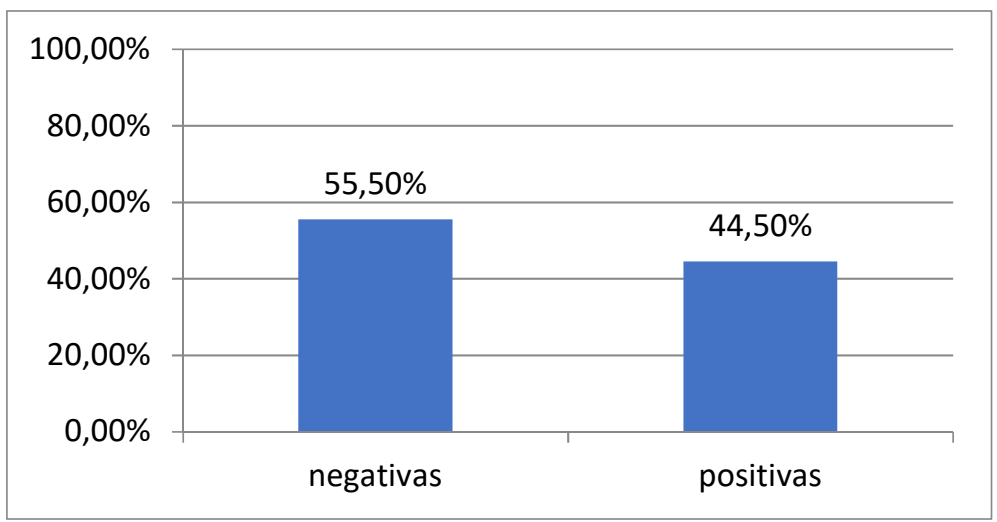

Figura 7: Frequência positivas e negativas das duzentas amostras fecais proveniente de humanos da cidade de Corumbá/MS.

Dentre as espécies de parasitas intestinais analisados (Fig.12) verifica-se uma maior prevalência para os protozoários Entamoeba coli, 34,83\%, seguido de E. nana com 24,70\%, Giardia lamblia 20,22\%, Entamoeba histolytica com 16,85\%, Blastocystis spp. com 3,37\% e Sarcocystis spp. 3,37\%. Para os helmintos o que apresentou maior prevalência foi Trichuris sp. com 7,80\% seguido do Acaris lumbricoides, 4,49\%, Enterobius vermiculares 1,12\%, Taenia sp. 1.12\% Fasciola hepatica 1,12\%.

Assim destaca-se uma maior prevalência por parasitas comensais como E. coli na forma cística (Fig.8) seguido de E. nana, portanto são parasitas não patogênicos, porém são importante indicador das condições sócio- sanitária, pois tem os mesmos mecanismo de transmissão como outros protozoários patogênicos (BRITO et al., 2013), no entanto estes resultados condiz com os resultados de Santos et al. (2010) em um estudo realizado com crianças no Amazonas, onde foi diagnosticado uma prevalência de $35,00 \%$ para E. coli.

Dentre os protozoários patogênico foram encontrados maior frequência para as formas císticas de Giardia lamblia (Fig.9) é um parasita mais frequente em crianças na faze escolar, pois apresenta distribuição em várias regiões do Brasil, a via de contaminação fecal-oral, contato direto de pessoas - pessoas principalmente nas famílias pobres, devido as precárias condições de moradia e falta de higiene pessoal bem a ingestão de alimentos e principalmente água contaminados por cistos viáveis (MELO et al., 2010), no entanto este resultados corrobora com o trabalho de Belloto et al. (2011) realizado em escolares no Município de Mirassol em São Paulo, onde obteve 15,16\% para Giardia lamblia, e uma prevalência de 21,4\% para Giardia lamblia no trabalho realizado com crianças de creches de Rio Verde/GO (ZAIDEN et al., 2008). 


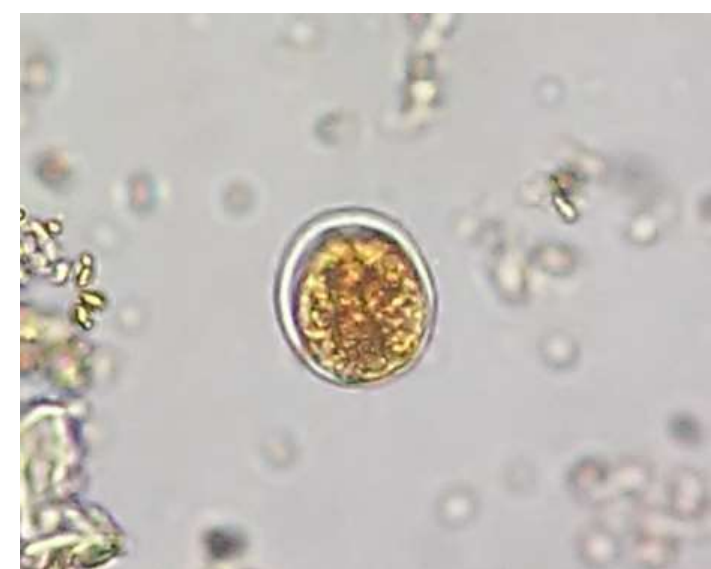

Figura 8: Forma cística de E. coli encontrado em fezes de humanos de Corumbá/MS.

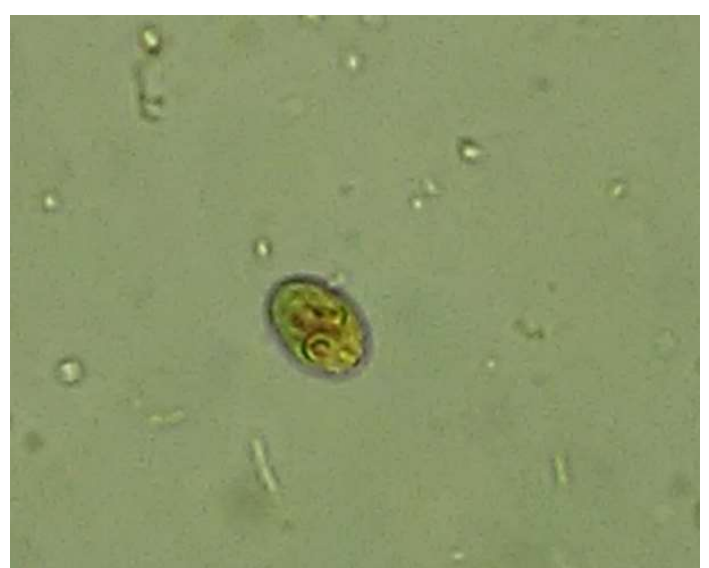

Figura 9: Forma cística da Giardia lamblia encontrada em fezes de humanos de corumbá/MS.

O protozoário $E$. histoliytica encontrado na forma císticas apresentou uma prevalência alta quando comparado aos resultados na literatura como o de Gomes et al. (2010) em estudo realizado em escolares de Água do Miranda e Bonito MS, onde obteve uma ocorrência de 3,5\% para E. histolytica, e assemelha com o resultado de Kunz et al. (2008) em escolares de Florianópolis SC, onde obteve 15,3\% para E. histolytica.
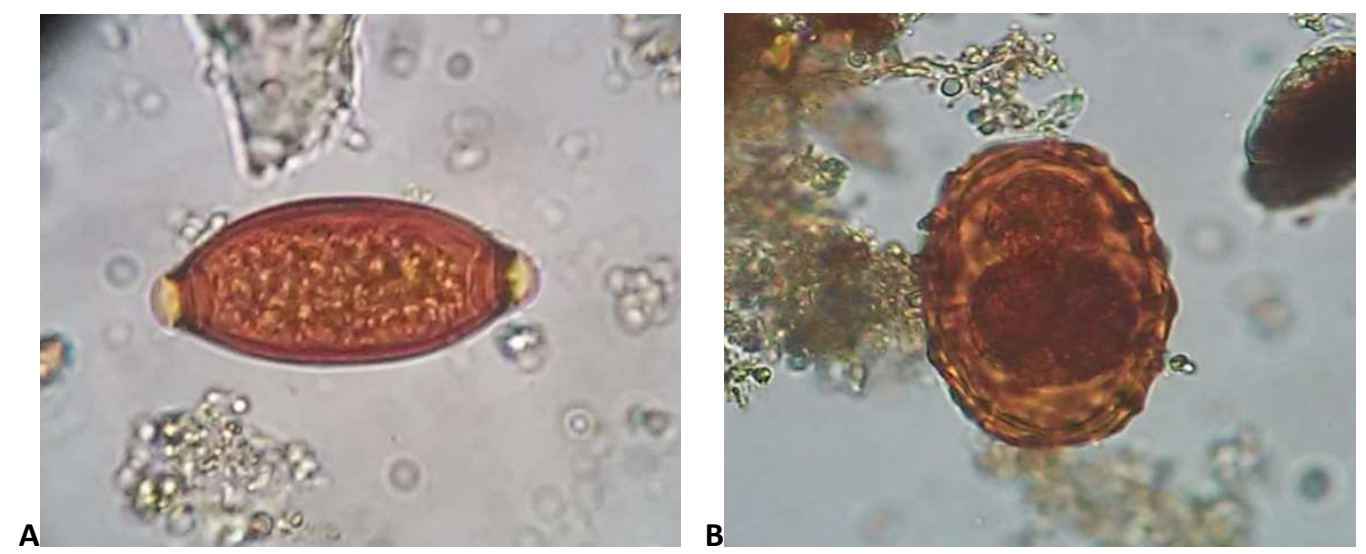

Figura 10: Ovos de T. trichiura - $\underline{A}$ e ovos de A. lumbricoides-B $\underline{B}$ diagnosticados em fezes de humanos do município de Corumbá/MS.

Dentre os helmintos houve uma maior ocorrência para Trichuris trichiura encontrado na forma de ovos (Fg.10a) seguido de Acaris lumbricoides, também na forma de ovos (Fig.10b) a prevalência foi relativamente baixa comparado com os resultados de Carvalho et al. (2002) que obteve para T. trichiura 4,7\% e para Ascaris 10,3\% no Estado de Minas Gerais. Porém existem dados preocupantes como outro trabalho realizado no mesmo Estados em escolas apresentou uma frequência de 59,5\% para A. Iumbricoides e 36,6\% para T. trichiura (CARVALHO et al., 2002).

No entanto a ocorrência dos helmintos podem variar com maior ou menor frequência de acordo as condições ambientais favoráveis de cada região, além da falta de saneamento básico, higiene pessoal e precárias condições de moradia, apesar do T. trichiura e A. lumbricoides ter ampla distribuição são mais prevalente em regiões de clima quente e úmido e em condições sanitárias precárias favorece a contaminação ambiental e a sobrevivências dos ovos, Pois esses geohelmintos precisam do solo para completar seu ciclo de vida (NEVES, 2010). 


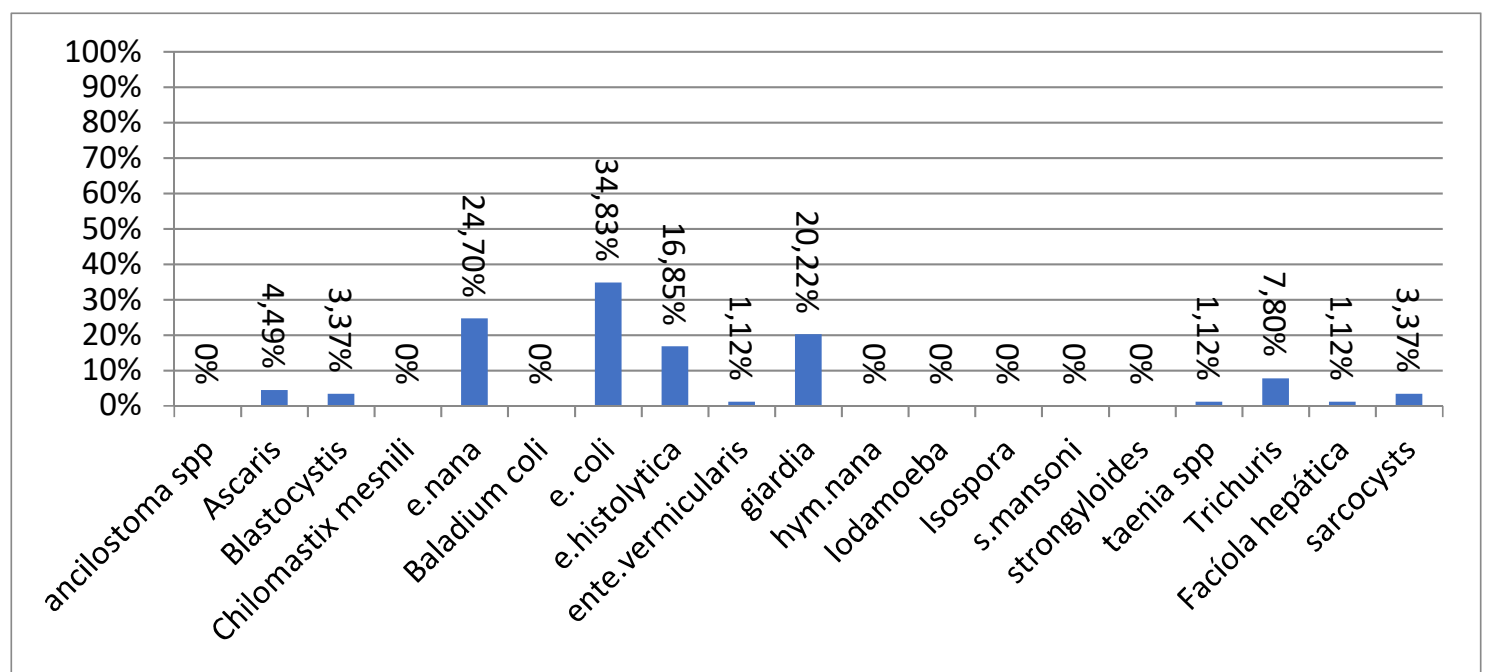

Figura 11: Frequência para todos os parasitas intestinais de humanos diagnosticados nas duzentas amostras fecais de crianças e adultos de Corumbá/MS.

Nos resultados analisados (Fig.12) foi encontrado uma maior prevalência para protozoários 86,90\% em relação aos helmintos $13,10 \%$, porém estes dados são considerado alto quando comparado com outros trabalhos nas literaturas como Guerreiro, et al. (2005) realizado em Amazônia onde foi encontrado uma prevalência para protozoários de $29,5 \%$ e Basso et al. (2008) em seu trabalho realizado em escolares de Caxias do Sul RS, onde houve uma prevalência de $34,5 \%$ para protozoários. No entanto este alto índice podem estar relacionado com falta de higiene pessoal e sanitária bem como a ingestão de água e alimentos contaminados por cistos de protozoários uma vez que são eliminados para o ambiente pelas fezes de pessoas infectadas, tornando-se uma fonte de contaminação.

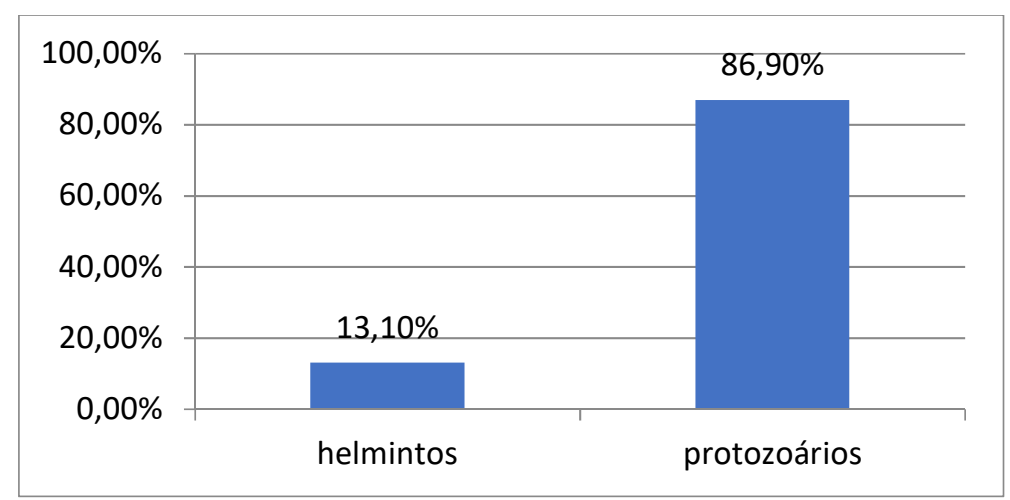

Figura 12: Frequência geral para helmintos e protozoários das duzentas amostras fecais de humanos analisadas na cidade de Corumbá/MS.

Nestes trabalho a variável sexo foi dividida em masculino e feminino (Fig.13), das duzentas amostras analisadas os resultados para helmintos e protozoários, mostram que houve maior predominância para o sexo feminino, no entanto não corrobora com do trabalho de Prado et al. (2001) que em seus resultados obteve a maior prevalência para o sexo masculino 70,1\% e feminino $62,1 \%$ e com o trabalho de Quadro et al. (2004), onde constatou para sexo masculino $65,1 \%$ e feminino $74,5 \%$. Portanto em teste Qui quadrado os sexos estão dispostos de forma independente e aleatória e a frequência de positividade para as parasitoses não dependem do sexo do indivíduo, (p: 0.5617978). 


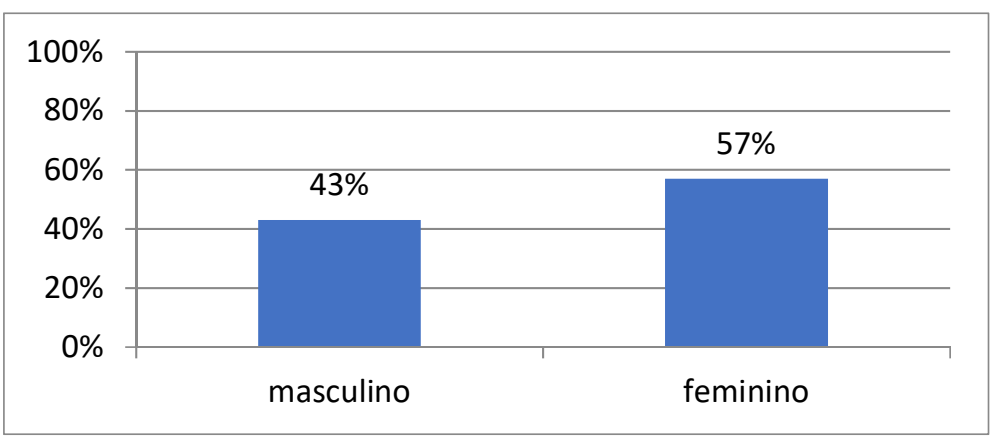

Figura 13: Frequência de parasitas intestinais diagnosticada por sexo masculino e feminino teste Qui- quadrado $\left(x^{2}\right)$ das amostra fecais proveniente de humanos da cidade de Corumbá/MS.

Os resultados para frequência geral por faixa etária constatou-se uma maior prevalência para crianças de 05 a 15 anos em relação aos adultos a partir de 16 anos, na (Fig.14) mostram 58,50\% crianças parasitadas, dentre essas um total de $99 \%$ estão parasitados por helmintos, o que é considerado alto quando compara com trabalho de Belloto et al. (2011) em estudo realizado em escolares com faixa etária entre de 02 a 15 anos na cidade Mirassol SP, obteve um percentual de 30,3\% de crianças parasitadas pelo menos uma espécie de parasitas intestinais.

No entanto assemelha-se com estudo de Gomes et al. (2010) realizado em escolares de Água do Miranda no mesmo estado MS que constatou uma prevalência de $41,7 \%$ de crianças contaminadas, porém existem resultados preocupantes como de Silva et al. (2012) em estudos realizado no município de Coari AM, que obteve $83,1 \%$ crianças contaminadas por parasitas intestinais.

Com relação os adultos a prevalência de $28,20 \%$ é considerável baixo, no entanto estes resultados corroboram com a literatura, pois a maior prevalência de crianças contaminadas podem estar relacionados que crianças são mais suscetíveis as infecções parasitárias do que os adultos até mesmo pela imaturidade imunológico, desconhecimento do hábito de higiene pessoal - sanitária bem como andar descalços, brincar no chão, e colocar alimento e objetos na boca com mãos sujas (VASCONCELOS et al., 2011). As infecções parasitárias podem causar problemas gastrointestinais como dores abdominais, diarreia, vômitos, anemia por falta de ferro, desnutrição e consequentemente deficiência mental e atraso no rendimentos escolar (COSTA et al., 2014).

Os resultados para consistência fecal (Fig.15) apresentam maior porcentagem para consistência fecal formada $77 \%$ e menor para diarreica $23 \%$, quanto o aspecto fecal apresentou $100 \%$ de normalidade, frente estes resultados percebe-se que há uma frequência elevada de indivíduos que albergam parasitas comensais. No entanto é preocupante que indivíduos assintomáticos podem ser uma fonte de contaminação pois disseminam parasitas entre pessoas que vivem ao seu redor, e servem como indicadores da falta do hábito de higiene pessoal-sanitária, principalmente pessoas que manipulam alimentos, pois a contaminação é via fecal-oral, portanto os parasitas comensais tem as mesmas via de transmissão como outros parasitas intestinais patogênicos (BRITO et al., 2013). 


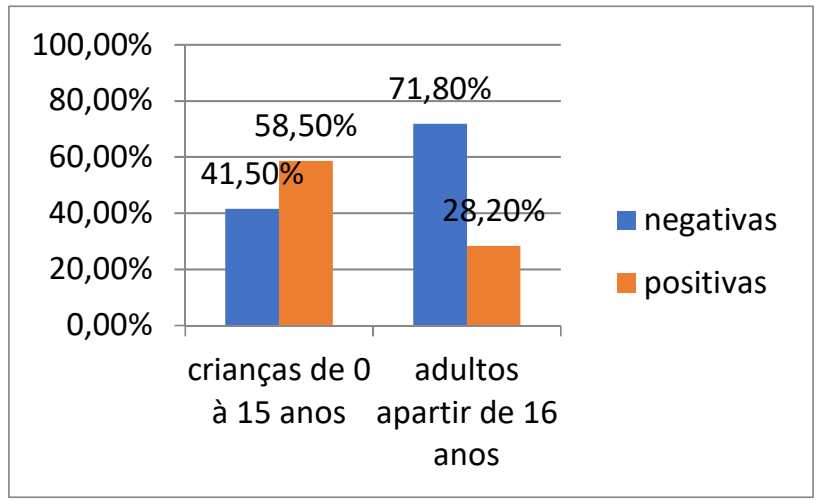

Figura 14: Frequência geral de infecção parasitária por faixa etária das duzentas amostras de humanos da cidade de Corumbá/MS.

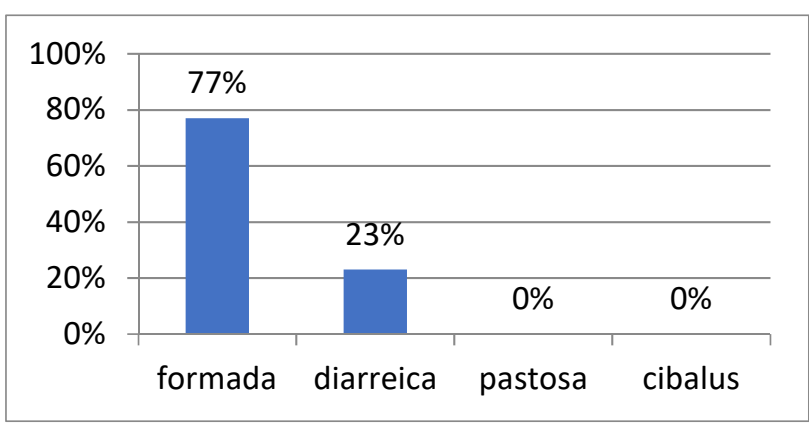

Figura 15: Frequência da consistência fecal para as duzentas amostras de humanos analisada em Corumbá/MS. Quanto ao aspecto fecal, $100 \%$ das amostras possuíam aspecto normal.

Com relação ao grau de parasitismo (fig.16) apresentou uma frequência de $65 \%$ para monoparasitados, ou seja, indivíduos que albergam uma espécie de parasitas intestinais, já para poliparasitismo apresentou uma frequência de $34 \%$ na população em estudo albergam mais de uma espécie de parasitas intestinais, deste os parasitas que mais apresentou associações foram as amebas Entamoeba coli seguida da Endolimax nana. No entanto estes resultados corroboram com os resultados do trabalho de Silva et al. (2012) realizado em na cidade de Coari estado do Amazonas onde obteve uma frequência de 55,5\% de monoparasitismo, e 36,5 nos resultados de Andrade et al. (2011) no estado de Minas Gerais.

Frente ao exposto a alta frequência de associação por mais uma espécie de enteroparasitas podem estar relacionados as condições socioeconômico da população, o que aponta para um maior rico de contaminação ambiental, pois as parasitoses estão associados as inadequadas faltas de higiene- sanitária bem como a ingestão de alimentos e principalmente água contaminadas por cistos de protozoários e ovos de helmintos (OLIVEIRA et al., 2012).

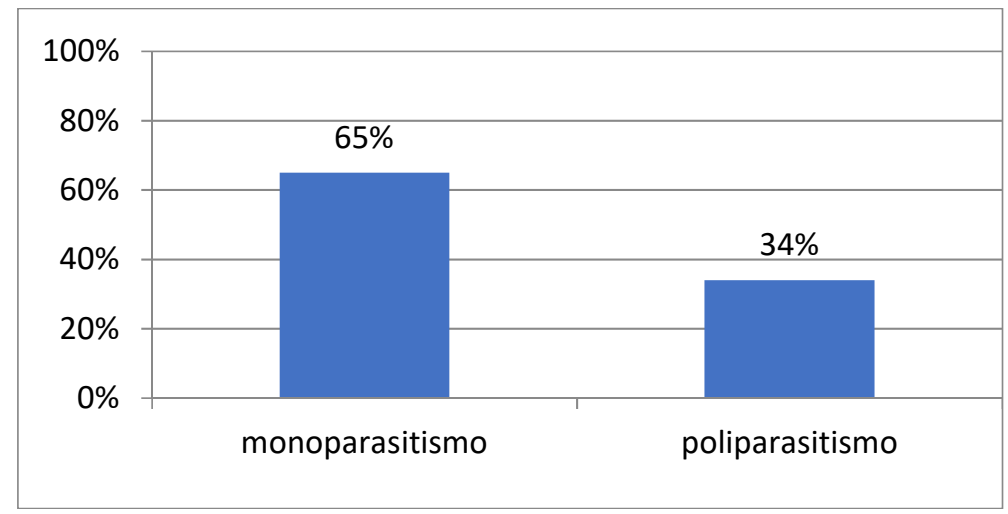

Figura 16: Frequência simples para poliparasitismo e monoparasitismo das duzentas amostras fecais de humanos do município de Corumbá/MS.

\section{CONCLUSÕES}

Frente os resultados, este trabalho foi possível perceber uma alta prevalência de enteroparasitas intestinais $44,50 \%$ da população em estudo está infectada por pelo menos uma espécie de parasitas, das duzentas amostras analisadas obteve uma predominância de 86,90\% de positividade para protozoários, entretanto indica que o município de Corumbá ainda se encontra em deficiência de infraestrutura, no 
entanto a população necessita de melhores condições de saneamento básico bem como hábitos de higiene pessoal.

Quanto ao grau de parasitismo apresentou um alto índices de pessoas contaminadas por mais de uma espécie de parasitas intestinais o que é preocupante pois os enteroparasitas estão associados as precárias condições de moradia decorrente de países subdesenvolvidos atingindo as famílias de nível socioeconômico baixo, causando aglomeramentos de pessoas morando em uma residência. A prevalência de indivíduos que albergam parasitas não patogênico foi alta o que refletem uma fonte de disseminação entre membros da família por outros parasitas patogênicos.

Diante do exposto há necessidade realizar mais trabalhos na população deste município ou no estado para obter mais dados relevantes, e que haja ação de controle das doenças parasitárias e melhoria na qualidade de vida dessas pessoas, pois há necessidade de intervenções de políticas públicas para implantação de projetos educativo com a participação da população, pois a profilaxia é uma das medidas preventivas não só pela ausência da doença mas pelo bem estar das famílias.

\section{REFERÊNCIAS}

AVELAR, I. A.. Prevalência de Parasitoses Intestinais em Crianças da Escola Municipal Pedro Silva Neiva, Assentamento do Sem Terra (Jambreiro), Paracatu (MG). Monografia. (Graduação em Biomedicina) - Faculdade Tecsoma, 2012

ANDRADE, E. C.; LEITE, I. C. G.; RODRGIUES, V. O.; CESCA, M. G.. Parasitoses Intestinais: uma revisão sobre seus aspectos sociais, epidemiológicos, clínicos e terapêuticos. Rev. APS, Juiz de Fora, v.13, n.2, p.231-240, 2010.

ANDRADE, E. C.; LEITE, I. C. G.; VIEIRA, M. T.; ABRAMO, C.; TIBIRICÁ, S. H. C.; SILVA P. L.. Prevalência de parasitoses intestinais em comunidade quilombola no Município de Bias Fortes, Estado de Minas Gerais, Brasil, 2008. Epidemiol. Serv. Saúde, v.20, n.3, p. 337-344, Brasília, 2011.

BRITO, A. M. G.; MELO, C. M.; REI, A. A.; BRITO, R. G.; MADI R. R.. Protozoário comensal em amostra fecal: parâmetro para prevenção de infecção parasitaria via fecal-oral. Scire Salutis, Aquidabã, v.3, n.2, 2013.

BELLOTO, M. V. T.; JUNIOR, J. E. S.; MACEDO, E. A.; PONCE, A.; GALISTEU, K. J.; CASRTO, E.; TAUYR, L. V.; ROSSIT, A. R. B.; MACHADO, R. L. D.. Enteroparasitoses numa população de escolares da rede pública de ensino do Município de Mirassol, São Paulo, Brasil. Rev Pan-Amaz Saude, v.2, n.1, p.37-44, 2011.

BASSO, R. M. C.; RIBEIRO, R. T. S.; SOLIGO, D. S.; RIBACKI, S. I.; JACQUES, S. M. C.; ZOPPAS, B. C.. Evolução da prevalência de parasitoses intestinais em escolares em Caxias do Sul, RS. Revista da Sociedade Brasileira de Medicina Tropical, v.41, n.3, p.263-268, 2008.

COSTA, P. S. C. B. V.; ARAUJO, I. B.; JUNIOR, P. R. G.; MOUSINHO, D. D.; COSTA, S. T. C. V.. Prevalência de anemia e enteroparasitoses em um laboratório da periferia da cidade de Parnaíba-Pi. R. Interd, v.7, n.3, p.71-76, 2014.
CINEMERMAN, B.. Parasitologia humana. 2 ed. São Paulo: Atheneu, 2001.

CARVALHO, O. S.; GUERRA, H. L.; CAMPOS, Y. R.; CALDEIRA, R. L.; MASSARA, C. L.. Prevalência de helmintos intestinais em três mesorregiões do Estado de Minas Gerais. Revista da Sociedade Brasileira de Medicina Tropical, v.35, n.6, p.597600, 2002.

EMBRAPA. Empresa Brasileira de Pesquisa Agropecuária. Contaminação de corpos d'água nas áreas Urbanas de Corumbá e Ledário. Corumbá: Embrapa Pantanal, 2005.

FARIAS, N. A.; CRHISTOVÃO, M. L.; STOBRE, N. S.. Frequências de parasitose em Cães (Canis familiaris) E Gatos (Felis catus dometica) em Araçatuba São Paulo. Rev. Bras. Parasitol, Araçatuba, v.1, n.4, p.53-60, 1995.

FERREIRA, H. S.; ASSUNÇÃO, M. L.; VASCONCELO, V. S.; MELO, F. P.; OLIVEIRA, C. G.; SANTOS, T. O.. Saúde de populações Marginalizadas: Desnutrição, Anemia e Enteroparasitoses em Crianças de uma Favela do 'Movimento dos Sem Teto', Maceió, Alagoas. Rev. Bras. Saúde Matern. Infantil, v.2, n.2, p.177-185-185, 2002.

GELATTI, L. C.; PEREIRA, A. S. S.; MENDES, A. P. S.; JASEM, D. F. A.; NASIMENTO, F. S.; BASTOS, H. L.; SOUZA, M. F.; PAULA, M. B. C.; SILVA, M. V. S.; REIS, N. O.. Ocorrência de Parasitos e Comensais Intestinais numa População de escolares do Município de Uruaçu, Goiás. Revista Fasem Ciências, v.3, n.1, 2013.

GUERRERO, A. F. H.; ALENCAR, F. H.; GUERRERO, J. C. H.. Ocorrência de enteroparasitas na população geronte de Nova Olinda do Norte, Amazonas, Brasil. Acta Amazonica, v.35, n.4, p.487-490, 2005.

GOMES, P. D. M. F.; NUNES, V. L. B.; KNECHTEL, D. S. K.; BRILHANTE, A. F.. Enteroparasitos em escolares do distrito 
Aguas do Miranda, município de Bonito, Mato Grosso do Sul. Revista de Patologia Tropical, v.39, n.4, p.299-307, 2010.

IBGE. Instituto Brasileiro de Geografia e Estatísticas. Censo demográfico de 2010. 2010.

KUNZ, M. O.; VIEIRA, A. S.; VARVAKIS, T.; GOMES, G. A.; ROSSETTO, A. L.; BERNARDINI, O. J.; ALMEIDA, M. S. S.; ISHIDA, M. M. I.. Parasitas intestinais em crianças de escola municipal de Florianópolis, SC/Educação ambiental e em saúde. Revista Biotemas, v.21, n.4, 2008.

LODO, M.; OLIVEIRA, C. G. B.; FONSECA, A. L. A.; CAPUTTO, L. Z.; PACKER, M. L. T.; VALENTI, V. E.; FONSECA, F. L. A. Prevalência de enteroparasitas em Município do interior paulista. Rev Bras Crescimento Desenvolvimento Hum, Bom Jesus dos perdões, v.20, n.3, p.769-777, 2010.

LUDWIG, C. M.; FREI, F.; FILHO F. A.; RIBEIRO-PÃES, J. T.. Correlação entre condições de saneamento básico e parasitoses intestinais na população de Assis, Estado de São Paulo. Revista da Sociedade Brasileira de Medicina Tropical, v.32, n.5, p.547-555, 1999

LUDWIG, C. M.; RIBEIRO, A. L. T.; CONTE, A. O. C.; J. T. D. Ocorrência de enteroparasitoses na população de um bairro da cidade de Cândido Mota, SP. J Health Sci Inst, v.30, n.3, p.271-6, 2012.

MORAES, R. G.. Parasitologia \& micologia humana. 2 ed. Rio de Janeiro: Cultura Médica, 1982

MARGAZÃO, M.; ARAÚJO, W. R.; PACHECO, J. M. S.; BATISTA, M. C. S.; BUSATTI, H. G. N. O.. Ocorrência de parasitoses intestinais em habitantes do município de Pará de Minas, MG, Brasil. Rev. Bras. Farm, v.91, n.4, p.183-8, 2010.

MARTINS, M. J.. Estudo dos Helmintos. Maceió: FUNASA, 2012.

MENEZES, V. F. P.; MEDEIROS, N. S.; DANI, C.. Prevalência de Enteroparasitoses em Escolares: uma Revisão do Perfil Encontrado nas Diferentes Regiões do Brasil, Revista Uniara, v.15, n.2, 2012

MELO, E. M.; FERRAZ, F. N.; ALEIXO, D. L. Importância do Estudo da Prevalência de Parasitos Intestinais de Crianças em Idade Escolar. SaBios: Rev. Saúde e Biol, v.5, n.1, p.4347, 2010.

NEVES, D. P.. Parasitologia humana. 11 ed. São Paulo: Atheneu, 2005.

NEVES, D. P.; Parasitologia humana. 2 ed. São Paulo: Atheneu, 2006.

NEVES, D. P.; Parasitologia humana. 11 ed. São Paulo: Atheneu, 2010.

NEVES, D. P.; Parasitologia humana. 12 ed. São Paulo: Atheneu, 2011.

OLIVEIRA, V. F.; AMOR, A. L. M.. Associação entre a ocorrência de parasitos intestinais e diferentes variáveis clínicas e epidemiológicas em moradores da comunidade Ribeira I, Araci, Bahia, Brasil. RBAC, v.44, n.1, p.15-25, 2012.
PEDRAZZINI, E. S.; MELO, D. A.; PRIPAS, S.; FICCI, M.; BARBOSA, C. A. A.; SANTORO, M. C. M.. Helmintoses Intestinais II: prevalência e correlação com renda, tamanho da família, anemia e estado nutricional. Rev. Saúde Públ., v. 22, n.5, 1988 .

PRADO, M. S.; BARRETO, M. L.; STRINA, A.; FARIA, J. A.; NOBRE, A.; JESUS, S.. Prevalência e intensidade da infecção por parasitas intestinais em crianças na idade escolar na Cidade de Salvador (Bahia, Brasil). Revista da Sociedade Brasileira de Medicina Tropical, v.34, n.34, p.99-101, 2001.

PEDROSA, E. F. N. C.; CABRAL, B. L.; ALMEIDA, P. R. S. F.; MADEIRA, M. P.; CARVALHO, B. D.; BASOTOS, K. M. S. B. VALE, J. M.. Contaminação ambiental de areia de praias de Fortaleza, Ceará. J Health Biol Sci, v.2, n.1, p.29-35. 2014.

REY, L.. Parasitologia. 3 ed. Rio de Janeiro: Guanabara Koogan S. A, 2001.

ROQUE, F. C.; BORGES, F. K.; SGNORI, L. G. H.; CHAZAN, M.; PIGATTO, T.; COSER, T. A.. Parasitos Intestinais: Prevalência em Escolas da Periferia de Porto Alegre, RS. 69 ed. NewsLab, 2005.

SILVA, C. G.; SANTOS H. A.. Ocorrência de parasitoses intestinais da área de abrangência do Centro de Saúde Cícero Idelfonso da Regional Oeste da Prefeitura Municipal de Belo Horizonte, Minas gerais. Revista de Biologia e Ciências da Terra, v.1, n.1, 2001.

SILVA, J. E. C.; PARENTE, B.; BURGOS, V. O.. Prevalência de parasitas intestinais em crianças de 05 a 12 anos, em Nova Alvorada do Sul, MS. Interbio, v.4, n.1, 2010.

SILVA, E. F.; VINICIUS, B. C. S.; FREITAS, F. L. C.. Parasitoses intestinais em crianças residentes na comunidade Ribeirinha São Francisco do Laranjal, município de Coari, estado do Amazonas, Brasil. Revista de Patologia Tropical, v.41, n.1, p.97-101, 2012.

SOUZA, E. M. N.; FREITAS, C. M.. A produção científica sobre saneamento: uma análise na perspectiva da promoção da saúde e da prevenção de doenças. Eng Sanit Ambient, v.15, n.1, p.65-74, 2010

SANTOS, F. S.; GAMA, A. S. M.; FERNANDES, A. B.; JUNOR, J. D. D. R.; GUIMARÃES, J.. Prevalência de enteroparasitismo em crianças de comunidades ribeirinhas do Município de Coari, no médio Solimões, Amazonas, Brasil. Rev Pan-Amaz Saude, v.1, n.4, p.23-28, 2010.

VINHA, C.. Necessidade de uma Política Sanitária Nacional para o Combate às Parasitoses Intestinais. Médico Sanitarista do Ministério da Saúde. Sorocaba, 1975.

VISER, S.; GEATTI, L. L.; CARVALHO, R. A. C.; GUERREIRO, J. C. $H$.. Estudo da associação entre fatores socioambientais e prevalência de parasitose intestinal em área periférica da cidade de Manaus (AM, Brasil), Ciência \& Saúde Coletiva, v.16, n.8, p.34-81, 2011.

VASCONCELOS, I. A. B.; OLIVEIRA, J. W.; CABRAL, F. R. F.; COUTINHO, H. D. M.; MENEZES, I. R. A.. Prevalência de parasitoses intestinais entre crianças de 4-12 anos no Crato, 
Estado do Ceará: um problema recorrente de saúde pública. Acta Scientiarum. Health Sciences, Maringá, v.33, n.1, p.3541, 2011.

SANTOS, F. S.; GAMA, A. S. M.; FERNANDES, A. B.; JUNIOR, J. D. D. R.; GUIMARÃES, J.. Prevalência de enteroparasitismo em crianças de comunidades ribeirinhas do Município de Coari, no médio Solimões, Amazonas, Brasil. Rev Pan-Amaz Saude, v.1, n.4, p.23-28, 2010.

TEIXEIRA, J. C.; OLIVEIRA, G. S.; VIALI, A. M.; MUNIZ, S. S. Estudo do impacto das deficiências de saneamento básico sobre a saúde pública no Brasil no período de 2001 a 2009. Eng Sanit Ambient, v.19, n.1, p.87-96, 2014.

WHO. World Health Organization. Controle de helmintos nas crianças em idade escolar: um guia para os gerentes dos programas de controle. Geneva. 2002.

ZAIDEN, M. F.; SANTOS, B. M. O.; CANO, M. A. T.; JUNIOR, I. A. N.. Epidemiologia das Parasitoses Intestinais em Crianças de Creches de Rio Verde/Go. Medicina, Ribeirão Preto, v.41, n.2, p.182-7, 2008.

A CBPC - Companhia Brasileira de Produção Científica (CNPJ: 11.221.422/0001-03) detém os direitos materiais desta publicação. Os direitos referem-se à publicação do trabalho em qualquer parte do mundo, incluindo os direitos às renovações, expansões e disseminações da contribuição, bem como outros direitos subsidiários. Todos os trabalhos publicados eletronicamente poderão posteriormente ser publicados em coletâneas impressas sob coordenação da Sustenere Publishing, da Companhia Brasileira de Produção Científica e seus parceiros autorizados. Os (as) autores (as) preservam os direitos autorais, mas não têm permissão para a publicação da contribuição em outro meio, impresso ou digital, em português ou em tradução. 